\title{
Risk Management of Osteoporosis in Postmenopausal Women; A Study of Women In a Teaching Hospital
}

\author{
Chander Kumar Lohana ${ }^{1} \&$ Nafisa Samir ${ }^{1}$ \\ ${ }^{1}$ Department of Family Medicine and Public Health, Sultan Qaboos University Hospital, PO Box 38, PC 123, \\ AL-Khod, Muscat, Oman \\ Correspondence: Chander Kumar Lohana, Department of Family Medicine and Public Health, Sultan Qaboos \\ University Hospital, PO Box 38, PC 123, AL-Khod, Muscat, Oman. E-mail: cklohano@hotmail.com
}

Received: December 7, 2015 Accepted: February 14, $2016 \quad$ Online Published: February 29, 2016

doi:10.5539/gjhs.v8n11p36

URL: http://dx.doi.org/10.5539/gjhs.v8n11p36

\begin{abstract}
Background: Postmenopausal females are susceptible to osteoporosis due to clinical manifestations. It not only causes morbidity; but, is considered to strikingly decline quality of life among patients. Among different developing regions, the prevalence rate of osteoporosis among postmenopausal women is alarming in the face of poor management and awareness about its risk factors.
\end{abstract}

Aim: The aim of this study was to investigate the incidence of osteoporosis and its known risk factors among postmenopausal women appearing for bone mineral density in Karachi.

Methodology: This descriptive cross-sectional study was undertaken from the period of "March 2006 to March 2007" in "Aga Khan University hospital", Karachi. A total of 245 females, who came to the radiology department at Aga Khan Hospital for DXA scan, were recruited. All the relevant data was collected through questionnaires. Data analysis was undertaken by using SPSS version 11.5 to generate frequencies and proportion percentages.

Results: The study demonstrated that 99 females (40\%) amongst all subjects were osteopenic, 114 females (47\%) were osteoporotic; whereas, 32 females (13\%) were normal. A decline was observed in bone mineral density with advancing age and duration of menopause. The distribution of osteoporosis was observed to be common in women, who had more children, low BMI, history of prior fractures, history of premature menopause, and were avoiding exercise.

Conclusion: This study confirmed a high frequency of osteoporosis and osteopenia in postmenopausal women. Therefore, early screening is required to detect the decrease in bone mineral density among postmenopausal females to prevent fragility fracture. There is an imperative requirement for vast public awareness in this regard.

Keywords: osteoporosis, osteopenia, postmenopausal women, menopause, women, bone density, risk factors, Bone mineral density (BMD)

\section{Introduction}

Postmenopausal osteoporosis is considered as a leading public health issue linked with a significant socioeconomic burden and mortality as well as morbidity (Keen, 2003; Jackson \& Mysiw, 2014). It is referred to as a skeletal disorder, which is exemplified by weak bones, leading to an increased threat of fragility fractures (Edwards et al., 2013). Osteoporosis is usually classified into primary class and secondary class depending upon its underlying cause (Christiansen, 1995; Harrop et al., 2004). Though, the impact of osteoporosis considerably varies between different nations, due to the utilization of different public health resources and population differences. The osteoporotic fracture and its prevalence are known to increase with an individual's growing age (Miura, Saavedra, \& Yamamoto, 2008). This condition has so far impacted more than 75 million people in USA, Japan, and Europe. It has also caused more than 2.3 million fractures annually in Europe and USA (World Health Organization, 2003). Analogous to coronary heart disease, the long-term risk for vertebral, hip, and forearm fracture is roughly estimated to be $40 \%$ (World Health Organization, 2003). It is a severe issue in Pakistan due to repeated pregnancies, early marriages, and malnutrition (Noor, Chinoy, \& Sadruddin, 1999).

Osteopenia is considered as another public health concern, in which content of mineral and protein is reduced within bone tissue; however, this condition is less severe comparatively to osteoporosis. The prevalence rate of 
this public issue is also increasing; however, osteoporosis seems to be highly emergent among postmenopausal women. Postmenopausal osteoporosis is a chronic disease that requires planned chronic treatment (Ostbye et al., 2005). Nevertheless, this condition produces no or little clinical manifestations, due to which the patients often go undiagnosed until a fracture occurs (Faisal-Cury \& Zacchello, 2007). Due to this reason, early diagnosis of this condition is extremely necessary for reducing the hazard of fractures (Baim \& Leslie, 2012). Yet, effective tools for diagnosis are not available currently to assist primary care physicians in detecting an individual for developing postmenopausal osteoporosis. Examining BMI or bone mineral density is recognized as a necessary approach in the early diagnosis of osteoporosis; in order that, effectual therapeutic and preventive measures can be undertaken at the earliest (Kelly et al., 1988). One of the gold standards for examining bone density is "Dual Energy X-ray Absorptiometry (DXA)". It is a helpful tool for both the appendicular as well as the axial skeleton. However, the most commonly utilized modality inspecting the bone density is calcaneal QUS (Quantitative Ultra Sonography). This is a cost effective and portable technique and lacks harmful radiation effect. This technique is also practical for the screening of osteoporosis and osteopenia (Kung et al., 2005; Mohr et al., 2004).

Identification of osteoporosis risk factors will help health care providers in selecting individuals for intervention and evaluation (Kanis, 1994). It is, therefore, imperative to examine not only the risk factors coupled with osteoporosis per se, which are renowned moderately but also their prevalence in the general population. Many studies have demonstrated that there are numerous risk factors that need to be taken into account, which mainly include treatment or being underweight, family history, history of previous fractures, early menopause, and age (Moberg et al., 2014). The distribution of the factors was also examined previously among which majority of these studies have been conducted with females over 65 years old (Ji \& Yu, 2015). As a result, limited knowledge and results are available on different prevalent risk factors for osteoporosis in postmenopausal women (aged between $50 \& 65$ ). Therefore, the prevention scheme of osteoporosis needs to be focused on significantly declining incidences of fractures and osteoporosis (Faisal-Cury \& Zacchello, 2007; Willson et al., 2015). Moreover, the risk factors for osteoporosis in the Caucasian population have been well documented (Jakobsen et al., 2013; Thomas-John et al., 2009); there is a dearth of data in Asian population (Aggarwal et al., 2011), as their environment and lifestyle are different from that of the western population. Hence, the current study is designed to fill this vacuum. Furthermore, this study will also assess the distribution of osteoporosis and its related risk factors in postmenopausal females appearing for bone mineral density testing in a teaching hospital in Karachi.

\section{Materials and Methods}

\subsection{Study Design}

It is a cross-sectional descriptive study conducted in the radiology department at Aga Khan University hospital, Karachi from March 2006 till March 2007. This study design was used to get advanced outcomes related to the research project (Mann, 2003). Due to time limitations and long working hours, a cross-sectional descriptive study best suits this study as compared to interviews. A survey permits to collect information from a large number of individuals, over a limited time.

\subsection{Population and Sample Size}

The study population consisted of a convenient (non-probability) sample of two hundred and forty-five postmenopausal women aged 40 to 86. Participation of the patients was voluntary. All of the postmenopausal women, who visited Aga Khan University Hospital (AKUH) radiology department for Dual-energy X-ray Absorptiometry (DXA) scan, were included in the study. Females who failed to give an informed consent were excluded. Assuming the prevalence of osteoporosis to be 19.9\%, (Ettinger, 1999) 5\% probability of type 1 error, $5 \%$ bound on error of estimation, and the sample size was calculated by the following formula:

1. Where ' $n$ ' is sample size

$$
n=\frac{\left(Z_{a}\right)^{2} p q}{d^{2}}
$$

2. ' $Z$ ' is constant

3. ' $\alpha$ ' $=5 \%$

4. ' $\mathrm{p}$ ' is expected prevalence $=19.9 \%$

5. ' $d$ ' is error bound $=5 \%$

$$
\mathrm{n}=\frac{(1.96)^{2} 0.199 \times 0.801}{0.05^{2}}
$$




\subsection{Data Collection}

The data set for this particular research study was collected by performing a questionnaire survey (Fowler Jr, 2013). A self-administered questionnaire was constructed and presented to the participants. This questionnaire was structured to aid analysis. Besides the demographics, multiple choice questions were used; this allowed the participant to select from a list of answers, by choosing the most appropriate answer in relation to clinical context, their experience, physical activity status, and history of fracture. Several attempts were made to alter questionnaire wordings for preventing ambiguity, and removing any doubt of what a specific question meant. The structure of the questionnaire was checked so that it would appear jargon free. Questions included in the questionnaire were thoroughly reviewed to determine their suitability for the projected audience.

\subsection{Study Variables}

The variables in this study included age, weight, height, premature menopause (before 45 years), calcium intake, BMI, exercise, smoking, family history of osteoporosis, alcohol, and corticosteroid therapy.

\subsection{Procedure and Instrument}

Family medicine residents were trained as per the protocol of the study. They were also informed about the inclusion and exclusion criteria. The study subjects were examined at the registration counter including females who visited for BMD testing for DXA scan at AKUH radiology department. The questionnaire was filled by the participants after obtaining the informed consent from the subjects.

\subsection{Statistical Analysis}

Data analysis and entry was performed by employing SPSS version 11.5. The questionnaires aided to complete the data set. Frequencies and proportion were applied for the analysis of categorical variables such as the presence of osteoporosis among all the women tested in order to meet the primary objectives. However, for variables such as age, weight and height "means" were calculated. All these factors were demonstrated as proportions (\% age).

\subsection{Ethical Consideration}

Ethical approval has been obtained from the research committee. During conscription, the aim and design of the questionnaire were demonstrated to the participants and mentioned as a preface on each questionnaire. Postmenopausal women gave their consent to answer the questionnaire.

\section{Results}

In total, 245 postmenopausal women from radiology department at Aga Khan University Hospital participated in the survey. Ages ranged from 40 to 86 years, with an average of 59.77 years $(\mathrm{SD} \pm 8.13)$. The majority of women were between $139 \mathrm{~cm}$ and $180 \mathrm{~cm}$ in height, mean being $152.43 \mathrm{~cm}(\mathrm{SD} \pm 6.24)$. Mean BMI ranged $15-45$, with an average of $29.33(\mathrm{SD} \pm 5.35)$. The mean weight of postmenopausal females was calculated to be $67.04 \mathrm{~kg}$ $(\mathrm{SD} \pm 12.85)$ with the weight of participants as low as $33 \mathrm{~kg}$ to as high as $104 \mathrm{~kg}$. The mean age/duration of menopause among study subjects was 11.99 years $(\mathrm{SD} \pm 7.60)$. The mean number of children of these postmenopausal women was calculated to be $13(\mathrm{SD} \pm 2.17)$ with lowest being 0 and highest being 13.

Table 1. Demographic and Osteoporosis Associated Risk Factors in Study Subjects

\begin{tabular}{|c|c|c|c|}
\hline Parameters & $\begin{array}{l}\text { Osteoporosis } \\
\left(\begin{array}{l}n=114) \\
\text { mean } \pm \text { SD }\end{array}\right.\end{array}$ & $\begin{array}{l}\text { Osteopenia } \\
(\mathrm{n}=99) \\
\text { mean } \pm \mathrm{SD}\end{array}$ & $\begin{array}{l}\text { Normal } \\
(n=32) \\
\text { mean } \pm \text { SD }\end{array}$ \\
\hline Age ( Years ) & $62.62 \pm 9.21$ & $57.76 \pm 9.99$ & $55.84 \pm 4.47$ \\
\hline Weight ( Kg ) & $62.14 \pm 12.3$ & $71.73 \pm 11.9$ & $70 \pm 11.5$ \\
\hline Height ( cm) & $151.12 \pm 6.46$ & $153.20 \pm 5.76$ & $152.43 \pm 6.01$ \\
\hline BMI $\left(\mathrm{Kg} / \mathrm{m}^{2}\right)$ & $27.75 \pm 5.23$ & $31.00 \pm 5.06$ & $29.33 \pm 5.35$ \\
\hline Duration of menopause ( Years ) & $15.01 \pm 8.09$ & $10.13 \pm 6.06$ & $6.96 \pm 5.38$ \\
\hline Number of children & $4.44 \pm 2.24$ & $4.07 \pm 2.17$ & $3.34 \pm 1.70$ \\
\hline
\end{tabular}




\subsection{Distribution of Osteoporosis and Osteopenia in Postmenopausal Women}

The findings indicated that out of total 245 postmenopausal women, who underwent BMD measurement by DXA scan, 114 had osteoporosis and 99 were suffering from Osteopenia while only 32 postmenopausal women's BMD were normal as per standard WHO guidelines. The frequency percentage of osteoporosis and osteopenia measured by BMD is demonstrated in (Figure 1).

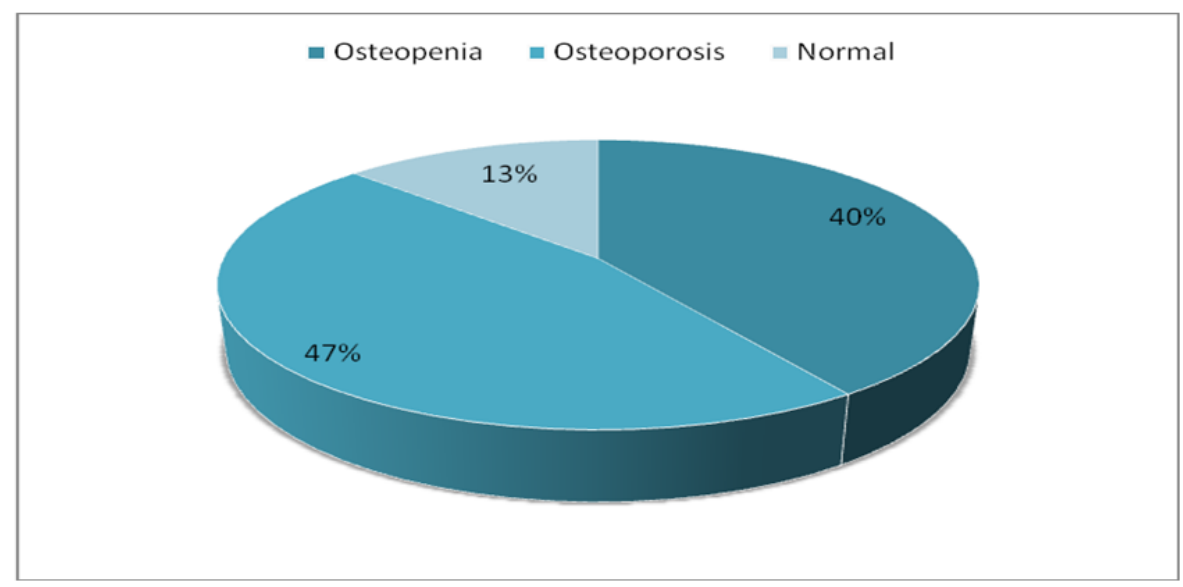

Figure 1. Distribution of Osteoporosis and Osteopenia in Postmenopausal Women

The conditions of osteoporosis and osteopenia were commonly found in the older postmenopausal women (Rosen, 2005). A decline was observed in BMI of osteoporotic women when compared with normal or osteopenic women. A significant increase in osteoporosis due to the increase in the number of children and duration of menopause was also observed (Table 1). In comparison to osteopenic and normal women, the frequency of exercise was found to be lower in osteoporotic women. In these females, history of smoking was pragmatic. However, history of alcohol intake was not evident. Personal history of fracture and history of premature menopause was also shown, which was known to increase significantly in postmenopausal women suffering from osteoporosis (Table 2).

Table 2. Comparison of Osteoporosis Associated Risk Factors in Different Groups of Postmenopausal Population $(\mathrm{N}=245)$

\begin{tabular}{lllll}
\hline No & Parameters & $\begin{array}{l}\text { Osteoporosis } \\
(\mathbf{n = 1 1 4})\end{array}$ & $\begin{array}{l}\text { Osteopenia } \\
(\mathbf{n = 9 9})\end{array}$ & $\begin{array}{l}\text { Normal } \\
(\mathbf{n}=\mathbf{3 2})\end{array}$ \\
\hline $\mathbf{1}$ & Exercise & & & \\
& Yes & $26(22.8 \%)$ & $27(27.3 \%)$ & $\mathbf{9 ( 2 8 . 1 \% )}$ \\
& No & $88(77.2 \%)$ & $72(72.7 \%)$ & $\mathbf{2 3 ( 7 1 . 9 \% )}$ \\
$\mathbf{2}$ & Smoking & & & \\
& Yes & $0(0 \%)$ & $2(2 \%)$ & $\mathbf{0 ( 0 \% )}$ \\
& No & $114(100 \%)$ & $97(97.9 \%)$ & $\mathbf{3 2}(\mathbf{1 0 0} \%)$ \\
$\mathbf{3}$ & Alcohol & & & \\
& Yes & $0(0 \%)$ & $0(0 \%)$ & $\mathbf{0 ( 0 \% )})$ \\
& No & $114(100 \%)$ & $99(100 \%)$ & $\mathbf{3 2}(\mathbf{1 0 0} \%)$ \\
$\mathbf{4}$ & H/O oral steroids & & & \\
& Yes & $2(1.8 \%)$ & $3(3 \%)$ & $\mathbf{0 ( 0 \% )})$ \\
& No & $112(98.2 \%)$ & $96(96.9 \%)$ & $\mathbf{3 2}(\mathbf{1 0 0} \%)$ \\
& & & & \\
\hline
\end{tabular}




\begin{tabular}{|c|c|c|c|c|}
\hline \multirow[t]{3}{*}{5} & $\mathrm{H} / \mathrm{O}$ fracture self & & & \\
\hline & Yes & $33(28.9 \%)$ & $17(17.1 \%)$ & $3(9.3 \%)$ \\
\hline & No & $81(71 \%)$ & $82(82.8 \%)$ & $29(90.6 \%)$ \\
\hline \multirow[t]{3}{*}{6} & H/O Mother's fracture & & & \\
\hline & Yes & $4(3.5 \%)$ & $2(2 \%)$ & $0(0 \%)$ \\
\hline & No & $110(96.4 \%)$ & $97(97.9 \%)$ & $32(100 \%)$ \\
\hline \multirow[t]{3}{*}{7} & Premature menopause & & & \\
\hline & Yes & $18(15.7 \%)$ & $7(7 \%)$ & $4(12.5 \%)$ \\
\hline & No & $96(84.2 \%)$ & $92(92.9 \%)$ & $28(87.5 \%)$ \\
\hline
\end{tabular}

\section{Discussion}

Post-menopausal osteoporosis is a common healthcare concern, characterized by the low mass of bone, leading to increased fragility of bones in postmenopausal females (Kanis et al., 2013). Therefore, this study aimed to assess the osteoporosis prevalence and its known risk factors in tertiary care settings. The study was undertaken at radiology department of the "Aga Khan University Hospital". The females meeting the inclusion criteria were examined by means of self-administered questionnaires including both the demographic data and risk factors. One essential component to preventing and target osteoporosis is the identification of risk factors (Eastell, 1998). Studies indicate that there is a marked variation in the risk of osteoporotic fractures from country to country indicating diversity in factors such as environment or lifestyle (Eisman et al., 1993). However, in the Caucasian population, risk factors for osteoporosis were documented well ${ }^{19}$. Limited studies and gap in data exist, indicating the distribution of osteoporosis in the Asian population, whose lifestyle and environment are different from that of the Western population (Koh et al., 2001).

In the current cross-sectional examination of postmenopausal females, 114(47\%) respondents were estimated to have osteoporosis, while only 32(13\%) were normal and 99(40\%) had Osteopenia. The independent osteoporosis predictors in the females were low BMI, advancing age, height, previous fracture, cigarette smoking, physical inactivity, low calcium intake, family history of osteoporotic fracture, premature menopause (before 45 years), excessive alcohol consumption, and corticosteroids therapy.

The prevalence of osteoporosis and osteopenia found in this study was higher than that found in the literature on similar studies. Sultan et al. (2006) conducted a study in a military hospital, Rawalpindi, by recruiting 105 postmenopausal women who underwent BMD measurement by Sahara clinical bone sonometer. The osteoporosis and osteopenia prevalence was $16.1 \%$ and 34\% respectively. Habiba, Ahmad, \& Hassan (2002) conducted a study in Peshawar and found that $75.3 \%$ of women are predisposed to osteoporosis from the total of 1000 postmenopausal women. This study was based on a score sheet pro forma, in which a simple calculation of scores were undertaken to examine the osteoporosis risk assessment estimation. However, the BMD measurements were not taken in this study. Another study examined the distribution of osteoporosis in Brazilian women, who were greater than 50 years old and were referred for bone density test. The prevalence was found to be 13.7\% (Silva et al., 2014). Conversely, Pinheiro (2010) recruited 627 women over the age of 50 and demonstrated that the osteoporosis prevalence in the femoral neck and lumbar spine neck of $18.8 \%$, and $28.8 \%$ respectively. The Osteoporosis diagnosis is undertaken through BMD (Hansen et al., 2014).

BMD is considered to be an age-dependent variable which demonstrates an increasing trend in the distribution of Osteoporosis with advancing age. Age is the primary determinant in osteoporosis. A majority of the studies indicate that advancing age is associated with increased fracture risk and low BMD (Harris, Blumentals \& Miller, 2007). Siris (2001) conducted a longitudinal observational study in USA. The author demonstrated that age is an essential risk factor to predict low BMD, even after being controlled for years, among other covariates as well as menopause, including BMI \& prior fracture. According to this screening based study, postmenopausal women are at an increased risk of developing osteoporosis (2002). This risk advances with an increase in age. This study demonstrated a significant decline in BMD with advancing age and increased osteoporosis frequency with postmenopausal duration period.

Weight-bearing physical exercises that work against gravity (like weight training, stair climbing and walking) assist in maintaining strong bones and are essential for bone remodeling (Lerner, 2006). The majority of the Pakistani females are housewives. They are known to spend a sedentary lifestyle with no or minimum physical 
activity that often exposes them to at the risk of diseases like, obesity, cardiac, diabetes, and stroke. In majority of the cross-sectional studies, a significant impact of weight-bearing exercise has been reported on different bones (Bradney et al., 1998; Bass et al., 1998). In current study, the frequency of exercise was considerably more in osteoporotic and osteopenic postmenopausal women as compared to normal postmenopausal women by BMD Smoking was another significant Osteoporosis risk factor. Only two osteopenic women were known to smoke which was low as compared to the western population. Moreover, no history of alcohol intake among study groups was reported.

A previous history of fracture places an individual at an enhanced risk (Meunier et al., 2004). In this study, personal fracture history considerably increased in an osteoporotic group as compared to osteopenic and normal subjects. However, maternal fracture history was observed in only 4 females in osteoporotic group and two in the osteopenic group. Systemic glucocorticoid therapy which lasts for more than two to three months for a specific disorder is a primary risk factor for fracture and loss of bone, specifically among postmenopausal women (Adachi et al., 2000). In this study, two females in the osteoporotic group and 3 in osteopenic group possessed an oral steroid history. A premature menopause, most specifically when induced surgically before 45 years of age, is thought to be a strong bone density determinant and enhanced fracture risk. Premature menopause history was comparatively more in an osteoporotic group than osteopenic and normal participants.

The study was limited to a relatively small patient non-probability sample. This sample failed to represent all the patients presenting osteoporosis condition. However, valuable information was obtained concerning its major risk factor. Moreover, since data has been collected data from the tertiary care center, and not from the community, therefore, the results cannot be generalized. The study was not conducted to examine and identify risk factors due to lack of comparison group but determined the distribution of risk factors in developing the country. After considering these limitations, the results of this study are further needed to be replicated in comparatively large samples within a community.

\section{Conclusion}

The Osteoporosis and Osteopenia prevalence were found to be high and alarming in postmenopausal women due to dietary and lifestyle risk. The study indicated that majority of the postmenopausal women predisposed to low BMD and osteoporosis are under diagnosed or under treated in this population. Based on these outcomes, there is a strong requirement for proper screening programs for postmenopausal women of this population so that preventive strategies can be effectively utilized by women at high risk. It is also advised that adequate management commences at an early stage for women suffering from this condition in order to decrease morbidity and mortality, which is connected with osteoporotic fractures. Nevertheless, the results of this study offer credibility to present recommendations for health care providers as an alert that Osteoporosis may be found in postmenopausal females and it may lead to increased risk of fracture. Hence, there is an urgent call for superior public understanding and awareness in this regard.

\section{Acknowledgments}

I would like my professor who guided me throughout the project. I am further grateful to the participants who showed their interest and trust in this project.

\section{Conflict of Interest}

The authors declare that there is no conflict of interests regarding the publication of this paper.

\section{References}

Adachi, J. D., Olszynski, W. P., Hanley, D. A., Hodsman, A. B., Kendler, D. L., \& Siminoski, K. G. (2000). Management of corticosteroid-induced osteoporosis. Semin Arthritis Rheum, 29, 228-51. http://dx.doi.org/10.1007/s11926-011-0173-y

Aggarwal, N., Raveendran, A., Khandelwal, N., Sen, R. K., Thakur, J. S., Dhaliwal, L. K., ... Manoharan, S. R. R. (2011). Prevalence and related risk factors of osteoporosis in peri-and postmenopausal Indian women. Journal of mid-life health, 2(2), 81. http://dx.doi.org/10.4103/0976-7800.92537

Baim, S., \& Leslie, W. D. (2012). Assessment of fracture risk. Current osteoporosis reports, 10(1), 28-41. http://dx.doi.org/10.1016/j.rdc.2011.07.001

Bass, S., Pearce, G., Bradney, M., Hendrich, E., Delmas, P. D., Harding, A., \& Seeman, E. (1998). Exercise before puberty may confer residual benefits in bone density in adulthood: studies in active prepubertal and retired female gymnasts. J Bone Miner Res, 13, 500-7. http://dx.doi.org/10.1359/jbmr.1998.13.3.500

Bradney, M., Pearce, G., Naughton, G., Sullivan, C., Bass, S., Beck, T., Carlson, J., \& Seeman, E. (1998). 
Moderate exercise during growth in prepubertal boys: Changes in bone mass, size, volumetric density, and bone strength: A controlled prospective study. $J$ Bone Miner Res, 13, 1814-21. http://dx.doi.org/10.1359/jbmr.1998.13.12.1814

Christiansen, C. (1995). Osteoporosis: Diagnosis and management today and tomorrow. Bone, 17, 513S-516S. http://dx.doi.org/10.1016/8756-3282(95)00345-0

Eastell, R. (1998). Treatment of postmenopausal osteoporosis. New England journal of medicine, 338(11), 736-746. http://dx.doi.org/10.1056/NEJM199803123381107

Edwards, M., Moon, R., Harvey, N., \& Cooper, C. (2013). Epidemiology and genetics of postmenopausal osteoporosis. Osteoporosis. Diagnosis and management, 1-14. http://dx.doi.org/10.1002/9781118316290.ch1

Eisman, J. A., Kelly, P. J., Morrison, N. A., Pocock, N. A., Yeoman, R., Birmingham, J., \& Sambrook, P. N. (1993). Peak bone mass and osteoporosis prevention. Osteoporosis International, 3(1), 56-60. http://dx.doi.org/10.1007/BF01621865

Elliott, M. E., Meek, P. D., Kanous, N. L., Schill, G. R., Weinswig, P. A., Bohlman, J. P., et al. (2002). Osteoporosis screening by community pharmacists: Use of National Osteoporosis Foundation resources. $J$ Am Pharm Assoc, 42, 101-110. http://dx.doi.org/10.1331/108658002763538134

Ettinger, B., Black, D. M., Mitlak, B. H., Knickerbocker, R. K., Nickelsen, T., Genant, H. K., et al. (1999). Reduction of vertebral fracture risk in postmenopausal women with osteoporosis treated with raloxifene: Results from a 3-year randomized clinical trial. JAMA, 282, 637-45. http://dx.doi.org/10.1001/jama.282.7.637

Faisal-Cury, A., \& Zacchello, K. P. (2007). Osteoporosis: Prevalence and risk factors among $>49$ year-old women in private practice environment. Acta Ortopédica Brasileira, 15(3), 146-150. http://dx.doi.org/10.1590/S1413-78522007000300005

Fowler Jr, F. J. (2013). Survey research methods. Sage publications. http://dx.doi.org/10.4135/9781452230184

Habiba, U., Ahmad, S., \& Hassan, L. (2002). Predisposition to osteoporosis in postmenopausal women. J coll physicians surg pak, 12, 297-301.

Hansen, C., Konradsen, H., Abrahamsen, B., \& Pedersen, B. D. (2014). Women's experiences of their osteoporosis diagnosis at the time of diagnosis and 6 months later: A phenomenological hermeneutic study. International journal of qualitative studies on health and well-being, 9. http://dx.doi.org/10.3402/qhw.v9.22438

Harris, S. T., Blumentals, W. A., \& Miller, P. D. (2007). Ibandronate and the risk of non-vertebral and clinical fractures in women with postmenopausal osteoporosis: Results of a meta-analysis of phase III studies. Current Medical Research and Opinion $® ;$; 24(1), 237-245. http://dx.doi.org/10.1185/030079908X253717

Harrop, J. S., Prpa, B., Reinhardt, M. K., \& Lieberman, I. (2004). Primary and secondary osteoporosis' incidence of subsequent vertebral compression fractures after kyphoplasty. Spine, 29(19), 2120-2125. http://dx.doi.org/10.1097/01.brs.0000141176.63158

Jackson, R. D., \& Mysiw, W. J. (2014). Insights into the Epidemiology of Postmenopausal Osteoporosis: The Women's Health Initiative. In Seminars in reproductive medicine, 32(6), 454-462. http://dx.doi.org/10.1055/s-0034-1384629

Jakobsen, A., Laurberg, P., Vestergaard, P., \& Andersen, S. (2013). Clinical risk factors for osteoporosis are common among elderly people in Nuuk, Greenland. International journal of circumpolar health, 72. http://dx.doi.org/10.3402/ijch.v72i0.19596

Ji, M. X., \& Yu, Q. (2015). Primary osteoporosis in postmenopausal women. Chronic Diseases and Translational Medicine, 1(1), 9-13. http://dx.doi.org/10.1016/j.cdtm.2015.02.006

Kanis, J. A. (1994). Assessment of fracture risk and its application to screening for postmenopausal osteoporosis: Synopsis of a WHO report. Osteoporosis International, 4(6), 368-381. http://dx.doi.org/10.1007/BF01622200

Kanis, J. A., McCloskey, E. V., Johansson, H., Cooper, C., Rizzoli, R., \& Reginster, J. Y. (2013). European guidance for the diagnosis and management of osteoporosis in postmenopausal women. Osteoporosis international, 24(1), 23-57. http://dx.doi.org/10.1007/s00198-012-2074-y 
Keen, R. W. (2003). Burden of osteoporosis and fractures. Current Osteoporosis Reports, 1(2), 66-70. http://dx.doi.org/10.1007/s11657-014-0187-y

Kelly, T. L., Slovik, D. M., Schoenfeld, D. A., \& Neer, R. M. (1988). Quantitative digital radiography versus dual photon absorptiometry of the lumbar spine. $J$ Clin Endocrinol Metab, 67, 839-844. http://dx.doi.org/10.1210/jcem-67-4-839

Koh, L. K. H., Sedrine, W. B., Torralba, T. P., Kung, A., Fujiwara, S., Chan, S. P., ... Osteoporosis Self-Assessment Tool for Asians (OSTA) Research Group. (2001). A simple tool to identify Asian women at increased risk of osteoporosis. Osteoporosis International, 12(8), 699-705. http://dx.doi.org/10.1007/s001980170070

Kung, A. W., Ho, A. Y., Ross, P. D., \& Reginster, J. Y. (2005). Development of a clinical assessment tool in identifying Asian men with low bone mineral density and comparison of its usefulness to quantitative bone ultrasound. Osteoporos Int, 16, 849e855. http://dx.doi.org/10.1007/s00198-004-1778-z

Lerner, U. H. (2006). Bone remodeling in post-menopausal osteoporosis. Journal of Dental Research, 85(7), 584-595. http://dx.doi.org/10.1002/jbmr.448

Mann, C. J. (2003). Observational research methods. Research design II: cohort, cross sectional, and case-control studies. Emergency Medicine Journal, 20(1), 54-60. http://dx.doi.org/10.1136/emj.20.1.54

Meunier, P. J., Roux, C., Seeman, E., Ortolani, S., Badurski, J. E., Spector, T. D., et al. (2004). The effects of strontium ranelate on the risk of vertebral fracture in women with postmenopausal osteoporosis. $N$ Engl J Med, 350, 459-68. http://dx.doi.org/10.1056/NEJMoa022436

Miura, S., Saavedra, O. L., \& Yamamoto, S. (2008). Osteoporosis in urban post-menopausal women of the Philippines: prevalence and risk factors. Archives of Osteoporosis, 3(1-2), 17-24. http://dx.doi.org/10.1007/s11657-008-0018-0

Moberg, L. M., Nilsson, P. M., Samsioe, G., \& Borgfeldt, C. (2014). Use of proton pump inhibitors (PPI) and history of earlier fracture are independent risk factors for fracture in postmenopausal women. The WHILA study. Maturitas, 78(4), 310-315. http://dx.doi.org/10.1016/j.maturitas.2014.05.019

Mohr, A, Barkmann, R, Mohr, C, Romer, F. W., Schmidt, C., \& Heller, M. (2004). Quantitative ultrasound for the diagnosis of osteoporosis. Rofo, 176, 610e617.

Noor, S., Chinoy, M. A., \& Sadruddin, N. (1999). Osteoporosis: A high risk hazard in old age. J Baqai Med Univ, 12, 47-50.

Ostbye, T., Yarnall, K. S., Krause, K. M., Pollak, K. I., Gradison, M., \& Michener, J. L. (2005). Is there time for management of patients with chronic diseases in primary care?. The Annals of Family Medicine, 3(3), 209-214. http://dx.doi.org/10.1370/afm.310

Pinheiro, M. M., dos Reis Neto, E. T., Machado, F. S., Omura, F., Yang, J. H., Szejnfeld, J., \& Szejnfeld, V. L. (2010). Risk factors for osteoporotic fractures and low bone density in pre and postmenopausal women. Revista de saude publica, 44(3), 479-485. http://dx.doi.org/10.1590/S0034-89102010000300011

Rosen, C. J. (2005). Postmenopausal osteoporosis. New England Journal of Medicine, 353(6), 595-603. http://dx.doi.org/10.1056/NEJMcp043801

Silva, A. C. V., da Rosa, M. I., Fernandes, B., Lumertz, S., Diniz, R. M., \& dos Reis Damiani, M. E. F. (2014). Factors associated with osteopenia and osteoporosis in women undergoing bone mineral density test. Revista Brasileira de Reumatologia (English Edition). http://dx.doi.org/10.1016/j.rbre.2014.08.011

Siris, E. S., Miller, P. D., Barrett-Connor, E., Faulkner, K. G., Wehren, L. E., Abbot, T. A., et al. (2001). Identification and fracture outcomes of undiagnosed low bone mineral density in postmenopausal women: Results from the National Osteoporosis Risk Assessment. JAMA, 286, 2815-22. http://dx.doi.org/10.1001/jama.286.22.2815

Sultan, A., khan, D. A., Mushtaq, M., \& Hassan, M. (2006). Frequency of osteoporosis and its associated risk factors in postmneopausal women in clinical practice at Rawalpindi. PakistanJ Pathol, 17, 115-118.

Thomas-John, M., Codd, M. B., Manne, S., Watts, N. B., \& Mongey, A. B. (2009). Risk factors for the development of osteoporosis and osteoporotic fractures among older men. The Journal of rheumatology, 36(9), 1947-1952. http://dx.doi.org/10.3899/jrheum.080527

Willson, T., Nelson, S. D., Newbold, J., Nelson, R. E., \& LaFleur, J. (2015). The clinical epidemiology of male 
osteoporosis: A review of the recent literature. Clinical epidemiology, $7,65$. http://dx.doi.org/10.2147/CLEP.S40966

World Health Organization. (2003). Prevention and management of osteoporosis: Report of a WHO Study Group. (Technical Report Series; 921). [Online] Retrieved from http://whqlibdoc.who.int/trs/WHO_TRS_921.pdf

\section{Copyrights}

Copyright for this article is retained by the author(s), with first publication rights granted to the journal.

This is an open-access article distributed under the terms and conditions of the Creative Commons Attribution license (http://creativecommons.org/licenses/by/3.0/). 